\title{
KINERJA PRODUKSI DAN NILAI TAMBAH AGROINDUSTRI JAMU BUBUK DI DESA ASTO MULYO KECAMATAN PUNGGUR KABUPATEN LAMPUNG TENGAH
}

\author{
(Production performance and added value of herbal agroindustry in the Asto Mulyo Village Punggur \\ Subdistrict Lampung Tengah District )
}

\author{
Measi Arsita, Muhammad Irfan Affandi, dan Suriaty Situmorang \\ Jurusan Agribisnis, Fakultas Pertanian, Universitas Lampung, J1. Prof. Dr. Soemantri Brojonegoro No. 1 \\ Bandar Lampung 35145, Telp 085216814738,e-mail : Irfanaffandi@fp.unila.ac.id.
}

\begin{abstract}
The purpose of the study is to analyze the production performance and added value of powdered herbal agroindustry. This research was carried out in Asto Mulyo Village, Punggur Subdistrict, Lampung Tengah District, which involved agroindustrial owners, industrial agencies, supermarket managers, self-service consumers, and community leaders. Data are analyzed quantitatively and statistically. The results of the research, herbal powder production performance is already good, with productivity of 5,16 $\mathrm{kg} / \mathrm{HOK}$, meaning that every one HOK of labor is able to produce as much as $5.16 \mathrm{~kg}$ powdered herbs, although the capacity value of powdeed herbal products is already high (91,00 percent). The R/C of agroindustry is 1.88, meaning that the agroindustry is good and profitable. The added value of each variant of different herbs, namely curcuma is amounting to Rp24,854.42 per kg of raw material; turmeric is amounting to Rp25,351.27 per $\mathrm{kg}$ of raw material, kencur of Rp12,352.29 per $\mathrm{kg}$ of raw material, and ginger in the amount of $R p 21,853.94$ per $\mathrm{kg}$ of raw material.
\end{abstract}

Key words: added value, herbal powder, production performance

\section{PENDAHULUAN}

Sektor pertanian di Indonesia merupakan salah satu sektor yang paling banyak menunjang perekonomian nasional, karena mayoritas penduduknya memiliki sumber pendapatan yang berasal dari sektor ini. Kondisi ini dibuktikan dengan kontribusi sektor pertanian terhadap Produk Domestik Bruto tahun 2017 sebesar 13,26 persen yang merupakan posisi tertinggi kedua setelah sektor industri pengolahan sebesar 20,27 persen (BPS 2017).

Menurut Nugroho (2011), sektor pertanian selain mensuplai makanan pokok dan bahan baku bagi sektor lain, juga berperan dalam menyediakan lapangan kerja serta devisa bagi Indonesia. Dengan melihat peran penting dari sektor pertanian, maka pembangunan sektor pertanian secara komprehensif dan holistik menjadi suatu keharusan. BPS (2018) menunjukkan peningkatan sektor pertanian, kehutanan, dan perikanan dipicu oleh meningkatnya produksi masa panen raya di beberapa subsektor seperti hortikultura dan perkebunan dengan masing- masing sebesar 22,86 persen dan 26,73 persen .
Berdasarkan Undang-Undang Nomor 13 tahun 2010, tanaman obat termasuk dalam kelompok tanaman hortikultura, yaitu tanaman yang menghasilkan buah, sayuran, florikultura, (termasuk jamur, lumut dan tanaman air yang berfungsi sebagai sayuran), dan bahan obat nabati. Di Indonesia, tanaman obat juga sering dikategorikan sebagai tanaman biofarmaka. Tanaman biofarmaka mencakup 15 (lima belas) jenis tanaman meliputi: jahe, laos/lengkuas, kencur, kunyit, lempuyang, temulawak, temuireng, temukunci, dlingo/dringo, kapulaga, mengkudu/ pace, mahkota dewa, kejibeling, sambiloto, dan lidah buaya (Kementerian Pertanian 2015).

Menurut Gunawan (2014), perusahaan industri obat dan industri farmasi menyerap produksi tanaman obat hingga mencapai 63 persen, sementara 23 persen merupakan konsumen rumah tangga, dan 14 persen untuk ekspor. Hal ini juga sesuai dengan data Kementerian Pertanian yang juga mengindikasikan bahwa total produksi tanaman obat di Indonesia 63 persen diserap oleh industri yang mencapai 1.023 perusahaan industri obat tradisional dan industri farmasi. Sementara itu, 14 persen diantaranya untuk tujuan ekspor, serta sisanya sebesar 23 persen untuk konsumsi langsung rumah tangga (Balitbangtan Deptan 2007). 
Sektor industri pengolahan Provinsi Lampung mengalami kenaikan setiap tahunnya. Pada tahun 2011, sektor industri pengolahan memiliki nilai PDRB sebesar Rp616 juta, kemudian mengalami kenaikan pada tahun 2012 menjadi Rp714 juta. Pada tahun 2013, nilai PDRB industri pengolahan Provinsi Lampung sebesar Rp803 juta rupiah, tahun berikutnya sebesar Rp993 juta, dan tahun 2015 sebesar Rp1.207 juta. Meningkatnya nilai PDRB industri pengolahan antara lain disebabkan oleh peningkatan industri farmasi, yaitu produk obat kimia dan obat tradisional (BPS Provinsi Lampung 2016).

Sektor pertanian menjadi salah satu pendukung jalannya agroindustri. Asto Mulyo merupakan salah satu desa yang berada di Kecamatan Punggur, Kabupaten Lampung Tengah yang memiliki potensi pertanian terbesar ketiga setelah Desa Toto Katon dan Sri Sawahan (BPS Kecamatan Punggur, 2016). Pertanian bukan sawah adalah semua lahan selain sawah seperti lahan pekarangan, huma, ladang, kebun, kolam, tambak, danau, rawa, dan lainnya. Tanaman obat keluarga dapat dengan mudah ditemui di pekarangan rumah warga Kecamatan Punggur, karena adanya kebijakan program dari kecamatan yang mewajibkan penduduk menanam tanaman obat keluarga (TOGA) minimal satu batang per rumah tangga. Adanya program dari kecamatan tersebut membuat tingginya jumlah tanaman obat keluarga di pekarangan warga Desa Asto Mulyo. Banyak masyarakat Desa Asto Mulyo yang memanfaatkan tanaman tersebut sebagai obatobatan dalam menyembuhkan berbagai penyakit. Kelemahan produk tanaman obat keluarga adalah tidak dapat bertahan lama (mudah busuk), sehingga banyak dari tanaman tersebut yang terbuang sia-sia.

Salah satu dari warga Desa Asto Mulyo, yaitu Ibu YY, memanfaatkan tanaman obat keluarga dengan mengolahnya menjadi jamu bubuk, yang dapat memberikan nilai tambah yaitu jamu dapat tahan lebih dari enam bulan. Jamu yang dijual Ibu YY antara lain temulawak, kunyit, kencur, dan jahe. Ibu YY sendiri sudah menjual produknya dari tahun 1996 dan mendapat izin dari Departemen Kesehatan pada tahun 2000, serta bermitra dengan salah satu swalayan yang ada di Kota Metro hingga saat ini.

Penilaian terhadap perkembangan agroindustri menjadi sangat penting untuk perencanaan suatu tujuan di masa yang akan datang. Penilaian kinerja agroindustri dapat dilihat dari produktivitas, kapasitas, dan pendapatan. Berdasarkan penilaian kinerja, maka dapat ditentukan bagaimana kinerja dari agroindustri tersebut (Prasetya dan Fitri 2009). Kegiatan agroindustri sebagai subsistem dari agribisnis diarahkan guna meningkatkan kemampuan pengelolaan usaha pertanian. Adanya sistem manajemen dan usaha pengelolaan terhadap hasil pertanian diharapkan mampu menciptakan nilai tambah hasil produk pertanian tersebut (Soekartawi 2000).

Suatu agroindustri untuk mencapai kinerja yang optimal, maka strategi harus dirumuskan dengan memperhatikan lingkungan. Selain itu, diperlukan analisis situasi mengenai lingkungan internal dan eksternal agroindustri jamu bubuk yang pada akhirnya akan dapat menghasilkan strategi-strategi yang berguna bagi perkembangan dan kemajuan agroindustri itu sendiri dan mampu bersaing merebut pangsa pasar.

Berdasarkan uraian latarbelakang, maka tujuan dari penelitian ini adalah menganalisis kinerja produksi dan nilai tambah agroindustri jamu bubuk Ibu YY di Desa Asto Mulyo Kecamatan Punggur Kabupaten Lampung Tengah.

\section{METODE PENELITIAN}

Metode penelitian yang digunakan dalam penelitian ini adalah studi kasus. Penelitian ini berlokasi di Desa Asto Mulyo, Kecamatan Punggur, Kabupaten Lampung Tengah. Penentuan lokasi penelitian dilakukan secara sengaja (purposive) dengan pertimbangan bahwa desa tersebut memiliki jumlah tanaman obat keluarga yang belum dimanfaatkan lebih lanjut. Waktu pengumpulan data dilakukan pada bulan Februari hingga Maret tahun 2018. Bahan baku yang dibahas dalam penelitian ini antara lain temulawak, kunyit, kencur, dan jahe.

Data yang dikumpulkan dalam penelitian ini adalah data primer dan data sekunder. Data primer diperoleh dari wawancara, dokumentasi, dan pencatatan langsung tentang keadaan di lapangan dengan bantuan kuesioner. Data sekunder diperoleh melalui analisis dokumen-dokumen dengan membaca dan mempelajari dokumen/arsip yang relevan dengan penelitian, yaitu Badan Pusat Statistik, Dinas Pertanian Provinsi Lampung, dan pustaka lainnya yang berhubungan dengan penelitian ini. Metode analisis data yang digunakan adalah analisis kuantitatif dan deskriptif kualitatif. Kinerja produksi dianalisis dari produktivitas, kapasitas, dan pendapatan. 
Produktivitas agroindustri dihitung dari unit yang diproduksi (output) dengan masukan yang digunakan (tenaga kerja dan mesin) yang dirumuskan sebagai :

$$
\text { Produktivitas }=\frac{\text { output }}{\text { input }} \times 100 \%
$$

Keterangan:

Output = Unit yang diproduksi $(\mathrm{kg})$

Input = Masukan yang digunakan, yaitu tenaga kerja dan mesin (HOK)

Kapasitas agroindustri diperoleh dari actual output, yaitu output berupa jamu bubuk, yang diproduksi (dengan satuan $\mathrm{kg}$ ) dan design capacity, yaitu kapasitas maksimal memproduksi jamu bubuk (dengan satuan $\mathrm{kg}$ ).

$$
\text { Kapasitas }=\frac{\text { Actual Output }}{\text { Design Capacity }} \times 100 \%
$$

Keterangan :

Actual Output = Output jamu bubuk nyata (real)yang diproduksi (kg)

Design Output = Kapasitas maksimal potensial produksi jamu bubuk $(\mathrm{kg})$

Pendapatan agroindustri menurut Soekartawi (2000) diperoleh dengan cara menghitung selisih antara total penerimaan yang diterima dari hasil usaha dengan total biaya produksi yang dikeluarkan. Tujuan analisis pendapatan adalah untuk menggambarkan tingkat keberhasilan suatu kegiatan usaha dan keadaan yang akan datang melalui perencanaan yang dibuat. Secara matematis, pendapatan usaha dirumuskan sebagai:

$$
\begin{aligned}
\pi & =\text { TR }-\mathrm{TC} \\
& =\mathrm{Y} \cdot \mathrm{Py}-(\mathrm{FC}+\mathrm{X} \cdot \mathrm{Px})
\end{aligned}
$$

Keterangan :

$\Pi \quad=$ Pendapatan $(\mathrm{Rp})$

TR = Penerimaan total agroindustri jamu bubuk (Rp)

TC = Biaya total yang dikeluarkan oleh pemilik agroindustri jamu bubuk (Rp)

$\mathrm{Y}=$ Produksi $(\mathrm{kg})$

Py $\quad=$ Harga hasil produksi $(\mathrm{Rp} / \mathrm{kg})$

$\mathrm{FC} \quad=$ Biaya tetap/Fixed cost $(\mathrm{Rp})$

$\mathrm{X}=$ Faktor produksi (input) (satuan)

$\mathrm{Px} \quad=$ Harga produksi ke $\mathrm{i}(\mathrm{Rp})$

Jumlah pendapatan menunjukkan apakah agroindustri menguntungkan atau tidak. Selain analisis pendapatan, terdapat analisis imbangan penerimaan dan biaya, yang dapat melihat keuntungan atau kerugian dari suatu agroindustri.
Analisis R/C dirumuskan sebagai:

$\mathrm{R} / \mathrm{C}=\frac{T R}{T C}$.

Keterangan :

$\mathrm{R} / \mathrm{C}=$ Nisbah penerimaan terhadap biaya

$\mathrm{TR}=$ Total revenue (penerimaan total)

$\mathrm{TC}=$ Total $\operatorname{cost}($ biaya total $)$

Jika R/C>1, maka agroindustri yang diusahakan mengalami keuntungan. Jika $\mathrm{R} / \mathrm{C}<1$, maka agroindustri yang diusahakan mengalami kerugian.

Nilai tambah dianalisis dengan metode Hayami, yaitu metode yang memperkirakan perubahan nilai bahan baku setelah mendapatkan perlakuan. Nilai tambah yang dihasilkan pada proses pengolahan tanaman obat keluarga menjadi jamu bubuk pada agroindustri jamu bubuk dihitung menggunakan metode Hayami.

\section{HASIL DAN PEMBAHASAN}

\section{Keadaan Umum Agroindustri}

Agroindustri jamu bubuk milik Ibu YY berdiri sejak tahun 1996 (telah berdiri selama 23 tahun). Status kepemilikan lahan yang dimiliki Ibu YY untuk usahanya adalah milik sendiri. Lokasi agroindustri jamu bubuk milik Ibu YY berada di Desa Asto Mulyo, Kecamatan Punggur, Kabupaten Lampung Tengah. Modal awal pertama kali mendirikan usaha yang dimiliki Ibu YY beserta keluarga adalah Rp500.000,00 pada tahun 1996. Merek dagang produk jamu bubuk milik Ibu YY adalah Raden Mas Joyo. Bahan baku yang digunakan antara lain temulawak, kunyit, kencur, dan jahe. Pemilik agroindustri jamu bubuk di Desa Asto Mulyo Kecamatan Punggur, yaitu Ibu YY. Berdasarkan hasil penelitian diketahui bahwa umur responden adalah 60 tahun, tergolong ke dalam usia produktif (15-64 tahun) (Purwanto 2008). Responden telah menempuh tingkat pendidikan SMA, sehingga responden responsif akan informasi dan teknologi yang berkembang pada saat ini.

\section{Proses Produksi}

Proses produksi pada agroindustri jamu bubuk terbilang semi modern, karena proses produksi dominan dilakukan secara manual, dan hanya menggunakan dua teknologi, yaitu mesin penggiling dan mesin perekat plastik. Tahapan proses produksi tanaman obat keluarga menjadi 
jamu bubuk adalah pencucian, penggilingan, pemerasan, pengadukan, dan pengemasan.

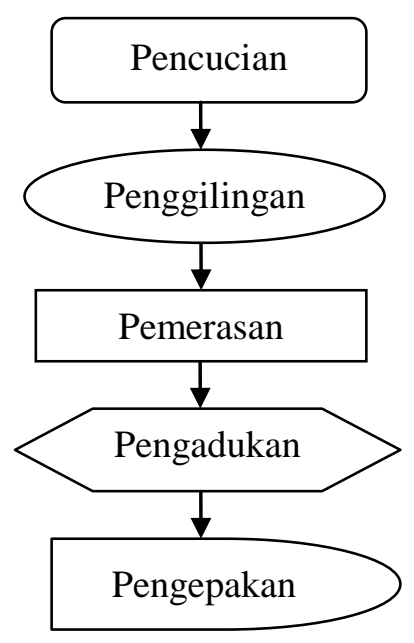

Gambar 1. Proses pembuatan jamu bubuk

Proses pencucian bertujuan untuk memisahkan kotoran yang menempel pada bahan baku, yaitu temulawak, kunyit, kencur, dan jahe. Kotoran yang sering terdapat pada bahan baku adalah tanah, karena tanaman obat keluarga merupakan tanaman yang berasal dari akar atau umbi-umbian, sehingga terdapat banyak sisa tanah yang menempel pada saat pencabutan. Pada tahap pencucian juga dilakukan pengirisan bahan baku yang rusak, misalkan karena busuk. Tahap pencucian pada agroindustri jamu bubuk di Desa Asto Mulyo Kecamatan Punggur masih menggunakan cara manual. Tenaga kerja yang melakukan tahap pencucian adalah tenaga kerja luar keluarga. Waktu yang dibutuhkan dalam proses ini sekitar 1 jam pada masing-masing (15 $\mathrm{kg}$ bahan baku). Lamanya waktu berdasarkan tingkat kesulitan dalam membersihkan bahan baku.

Proses penggilingan adalah proses pemisahan antara serat kulit bahan baku (temulawak, kunyit, kencur, dan jahe) dengan sarinya yang nanti akan diolah menjadi jamu bubuk. Proses penggilingan ini mengunakan mesin penggiling dan dilakukan oleh tenaga kerja dalam keluarga, yaitu bapak TT (suami Ibu YY). Dibutuhkan waktu 1 jam pada masing-masing (15 kg bahan baku).

Proses pemerasan menggunakan alat, yaitu lap pemeras, saringan, kuali, beserta baskom untuk hasil perasan. Proses ini dilakukan secara manual dan dikerjakan oleh tenaga kerja luar keluarga. Waktu yang dibutuhkan pada proses ini 1 jam pada masing-masing (15 kg bahan baku). Hasil dari proses ini adalah sari yang sudah bersih tanpa ada kotoran atau bahan lainnya dari masing-masing bahan baku (temulawak, kunyit, kencur, dan jahe), yang nantinya akan diolah kembali hingga menjadi jamu bubuk.

Proses pengadukan merupakan salah satu proses yang memiliki tingkat ketelitian yang sangat tinggi, karena bahan yang diolah menjadi jamu bubuk dapat berubah menjadi gulali apabila proses pengadukan dilaksanakan terlalu lama. Namun, bahan akan menjadi lembab dan mudah busuk apabila proses pengadukan dilakukan dengan waktu yang tidak tepat, yaitu terlalu cepat dari standar waktunya. Lamanya waktu proses pengadukan jamu bubuk di Desa Asto Mulyo Kecamatan Punggur berkisar 4 jam. Bahan-bahan yang sudah diperas sebelumnya akan diaduk dan direbus hingga berubah menjadi kristal-kristal bubuk jamu. Bahan baku utama yang digunakan pada masing-masing jenis adalah $15 \mathrm{~kg}$ (temulawak, kunyit, kencur, dan jahe), dengan bahan penunjang seperti garam sebanyak 5 sendok, dan gula $15 \mathrm{~kg}$. Gula bertujuan untuk pemanis sekaligus pengawet asli dalam produk jamu bubuk tersebut. Jamu bubuk milik Ibu YY dapat bertahan hingga 6 bulan dengan catatan tidak ditempatkan di bawah sinar matahari secara langsung atau dengan suhu lebih dari suhu normal ruangan, yaitu $30^{\circ} \mathrm{C}$.

Proses pengemasan bertujuan untuk perlindungan dari bahaya fisik, perlindungan dari kondisi iklim mikro luar kemasan (kelembaban, temperatur, cahaya, dsb), kemudahan transportasi, menentukan porsi yang sesuai untuk penjual atau konsumsi, dan pemberian informasi, karena kemasan dapat diberikan label yang mencantumkan berbagai informasi. Kemasan yang digunakan oleh agroindustri jamu bubuk adalah plastik ukuran $125 \mathrm{~g}$ per pack. Alat yang digunakan dalam proses pengemasan adalah perekat plastik atau filler.

\section{Kinerja produksi agroindustri jamu bubuk}

Analisis kinerja produksi pada agroindustri jamu bubuk dilihat dari aspek produktivitas, kapasitas, dan pendapatan. Bahan baku yang digunakan antara lain temulawak, kunyit, kencur, dan jahe. Masing-masing bahan baku memiliki nilai produktivitas, kapasitas, hingga pendapatan yang berbeda-beda. Produktivitas agroindustri dihitung dari unit yang diproduksi (output) dengan masukan yang digunakan (tenaga kerja dan mesin). Besarnya nilai produktivitas temulawak yaitu 5,40 $\mathrm{kg} / \mathrm{HOK}$, kunyit sebesar 4,89 kg/HOK, kencur sebesar 5,06 kg/HOK, dan jahe sebesar 5,31 $\mathrm{kg} / \mathrm{HOK}$. 
Tabel 1. Produktivitas agroindustri jamu bubuk Ibu YY di Desa Asto Mulyo Kecamatan Punggur, 2018

\begin{tabular}{clccc}
\hline No & Bahan baku & Output/bulan $(\mathbf{K g})$ & TK/bulan $(\mathbf{H O K})$ & Produktivitas $(\mathbf{K g} / \mathbf{H O K})$ \\
\hline 1 & Temulawak & 75,60 & 14,00 & 5,40 \\
2 & Kunyit & 68,40 & 14,00 & 4,89 \\
3 & Kencur & 70,80 & 14,00 & 5,06 \\
4 & Jahe & 74,40 & 14,00 & 5,31 \\
\hline \multicolumn{2}{l}{ Rata-rata } & $\mathbf{7 2 , 3 0}$ & $\mathbf{1 4 , 0 0}$ & $\mathbf{5 , 1 6}$ \\
\hline Sumber $:$ Data primer (diolah), 2018 & &
\end{tabular}

Nilai produktivitas yang didapat dari seluruh variasi jamu bubuk sebesar $5,16 \mathrm{~kg} / \mathrm{HOK}$, artinya setiap satu HOK tenaga kerja mampu menghasilkan atau memproduksi jamu bubuk sebanyak $5,16 \mathrm{~kg}$. Ringkasan poduktivitas jamu bubuk dapat dilihat pada Tabel 1 .

Kapasitas agroindustri diperoleh dari output berupa jamu bubuk yang diproduksi dibagi dengan kapasitas maksimal produksi. Berdasarkan penelitian Safitri, Abidin, dan Rosanti (2014), jika kapasitas $\geq 0,50$ atau 50 persen, maka agroindustri telah berproduksi secara baik. Jika kapasitas < 0,50 atau 50 persen, maka agroindustri berproduksi kurang baik. Besarnya nilai kapasitas pada agroindustri jamu bubuk pada penelitian ini adalah 0,91 atau 91 persen.

Nilai tersebut didapatkan dari hasil perhitungan nilai actual output sebesar 72,30 dibagi design capcity sebesar 79,20. Berdasarkan nilai tersebut, maka dapat dikatakan bahwa agroindustri jamu bubuk di Desa Asto Mulyo Kecamatan Punggur memiliki kapasitas yang tergolong baik. Rincian perhitungan kapasitas produksi agroindustri jamu bubuk dapat dilihat pada Tabel 2 .

Analisis pendapatan menggambarkan tingkat keberhasilan suatu kegiatan usaha dan keadaan yang akan datang melalui perencanaan yang dibuat. Jumlah pendapatan menunjukkan agroindustri menguntungkan atau tidak. Selain analisis pendapatan, terdapat analisis imbangan penerimaan dan biaya yang dapat melihat keuntungan atau kerugian dari suatu agroindustri.

Berdasarkan hasil perhitungan, maka total penerimaan jamu bubuk pada satu kali produksi adalah Rp2.313.600,00, dengan penerimaan masing-masing adalah temulawak Rp604.800,00, kunyit Rp547.200,00, kencur Rp566.400,00, dan jahe Rp595.200,00. Total biaya yang dikeluarkan pada satu kali produksi adalah Rp1.229.492,00 dengan biaya masing-masing adalah temulawak Rp262.364,09, kunyit Rp231.394,89, kencur Rp430.842,96, dan jahe Rp304.890,06.

Total pendapatan seluruh variasi jamu milik Ibu YY pada satu kali produksi adalah Rp1.084.108,00, dengan masing-masing pendapatan adalah temulawak sebesar Rp342.395,91, kunyit sebesar Rp315.805,11 kencur sebesar Rp135.557,04, dan jahe sebesar Rp290.309,94. Berdasarkan perhitungan tersebut, maka pendapatan dan penerimaan terbesar adalah pada temulawak, sedangkan pendapatan terkecil adalah pada kencur.

$\mathrm{R} / \mathrm{C}$ atas biaya total yang didapat dari masingmasing variasi jamu bubuk berbeda-beda, yaitu temulawak 2,31, kunyit 2,36, kencur 1,31, jahe 1,95 , dan keseluruhan variasi jamu bubuk sebesar 1,88 , yang artinya $\mathrm{R} / \mathrm{C}$ tersebut $>1$ dan agroindustri tersebut menguntungan dan layak untuk dijalankan.

Hal ini sejalan dengan penelitian Novia, Zakaria, dan Lestari (2013), dimana hasil penelitian tersebut menunjukkan pendapatan Agroindustri Beras Siger SU dan Agroindustri Beras Siger SS memiliki nilai $\mathrm{R} / \mathrm{C}$ atas biaya total lebih dari satu yaitu sebesar 1,26 dan 1,39 dengan rata-rata produksi beras siger perbulan sebesar $45,5 \mathrm{~kg}$ dan $100 \mathrm{~kg}$ serta rata-rata penerimaan perbulan sebesar Rp682.500,00 dan Rp700.000,00. Hal ini menunjukkan bahwa usaha agroindustri beras siger dapat dikatakan menguntungkan dan layak untuk dijalankan.

Tabel 2. Kapasitas agroindustri jamu bubuk Ibu YY di Desa Asto Mulyo Kecamatan Punggur, 2018

\begin{tabular}{clccc}
\hline No & Bahan baku & Output/bulan $(\mathbf{K g})$ & Output maks/bulan $(\mathbf{K g})$ & Kapasitas $(\mathbf{K g})$ \\
\hline 1 & Temulawak & 75,60 & 81,60 & 0,93 \\
2 & Kunyit & 68,40 & 72,00 & 0,95 \\
3 & Kencur & 70,80 & 76,80 & 0,92 \\
4 & Jahe & 74,40 & 86,40 & 0,86 \\
\hline & Rata-rata & $\mathbf{7 2 , 3 0}$ & $\mathbf{7 9 , 2 0}$ & $\mathbf{0 , 9 1}$ \\
\hline
\end{tabular}

Sumber : Data primer (diolah), 2018 
Tabel 3. Pendapatan agroindustri jamu bubuk sekali produksi Ibu YY di Desa Asto Mulyo Kecamatan Punggur, 2018

\begin{tabular}{|c|c|c|c|c|c|c|}
\hline No & Uraian & $\begin{array}{c}\text { Temulawak } \\
\text { (Rp) }\end{array}$ & $\begin{array}{c}\text { Kunyit } \\
\text { (Rp) }\end{array}$ & $\begin{array}{c}\text { Kencur } \\
\text { (Rp) }\end{array}$ & $\begin{array}{l}\text { Jahe } \\
\text { (Rp) }\end{array}$ & $\begin{array}{r}\text { Total } \\
\text { (Rp) }\end{array}$ \\
\hline 1 & Penerimaan & $604.800,00$ & $547.200,00$ & $566.400,00$ & $595.200,00$ & $2.313 .600,00$ \\
\hline \multirow[t]{18}{*}{2} & Biaya produksi : & & & & & \\
\hline & I. Biaya tunai : & & & & & \\
\hline & $\begin{array}{l}\text { Biaya variabel : } \\
\text { Bahan baku }\end{array}$ & $39.375,00$ & $28.500,00$ & 221.250 .00 & 8525000 & $374.375,00$ \\
\hline & Gula & $43.312,50$ & $39.187,50$ & $40.562,50$ & $42.625,00$ & $165.687,50$ \\
\hline & Garam & 36,09 & 32,66 & 33,80 & 35,52 & 138,07 \\
\hline & Plastik & $40.320,00$ & $36.480,00$ & $37.760,00$ & $39.680,00$ & $154.240,00$ \\
\hline & Label & $80.640,00$ & $72.960,00$ & $75.520,00$ & $79.360,00$ & $308.480,00$ \\
\hline & TKLK & $39.211,62$ & $35.477,18$ & $36.721,99$ & $38.589,21$ & $150.000,00$ \\
\hline & Biaya listrik & 435,68 & 394,19 & 408,02 & 428,77 & $1.666,67$ \\
\hline & Biaya tetap : & & & & & \\
\hline & Pajak & 5,06 & 4,57 & 4,74 & 4,98 & 19,34 \\
\hline & Total biaya tunai : & $243.335,95$ & $213.036,10$ & $412.261,05$ & $285.973,48$ & $1.154 .606,58$ \\
\hline & II. Biaya diperhitungkan : & & & & & \\
\hline & TKDK & $6.535,27$ & $5.912,86$ & $6.120,33$ & $6.431,54$ & $25.000,00$ \\
\hline & Penyusutan & 492,87 & 445,93 & 461,58 & 485,04 & $1.885,42$ \\
\hline & Kayu bakar & $12.000,00$ & $12.000,00$ & $12.000,00$ & $12.000,00$ & $48.000,00$ \\
\hline & Total biaya diperhitungkan : & $19.028,14$ & $18.358,79$ & $18.581,91$ & $18.916,58$ & $74.885,42$ \\
\hline & Total biaya : & $262.364,09$ & $231.394,89$ & $430.842,96$ & $304.890,06$ & $1.229 .492,00$ \\
\hline \multirow[t]{3}{*}{3} & Pendapatan : & & & & & \\
\hline & Pendapatan atas biaya tunai & $361.464,05$ & $334.163,90$ & $154.138,95$ & $309.226,52$ & $1.158 .993,42$ \\
\hline & Pendapatan atas biaya total & $342.435,91$ & $315.805,11$ & $135.557,04$ & $290.309,94$ & $1.084 .108,00$ \\
\hline \multirow[t]{3}{*}{4} & $\mathrm{R} / \mathrm{C}$ ratio : & & & & & \\
\hline & $\mathrm{R} / \mathrm{C}$ ratio atas biaya tunai & 2,49 & 2,57 & 1,37 & 2,08 & 2,00 \\
\hline & $\mathrm{R} / \mathrm{C}$ ratio atas biaya total & 2,31 & 2,36 & 1,31 & 1,95 & 1,88 \\
\hline
\end{tabular}

Hasil analisis pendapatan agroindustri jamu bubuk milik Ibu YY di Desa Asto Mulyo Kecamatan Punggur disajikan pada Tabel 3.

\section{Nilai tambah agroindustri jamu bubuk}

Menurut Asmara, Setiawan, dan Putri (2011), nilai tambah adalah penambahan nilai yang terdapat pada suatu produk setelah dilakukan proses pengolahan. Berdasarkan penelitian yang dilakukan pada agroindustri jamu bubuk di Desa Asto Mulyo, harga beli bahan baku per kg yang digunakan pada agroindustri jamu bubuk berbeda pada setiap jenisnya, yaitu kunyit senilai Rp2.000,00, temulawak Rp2.500,00, jahe Rp5.000,00, dan kencur sebesar Rp15.000,00. Perbedaan disebabkan oleh tingginya permintaan dan kurangnya stok produk. Harga jual output seluruh produk sama, yaitu Rp4.000,00/pack. Berat satu pack produk adalah 125 gram, maka harga jual produk per $\mathrm{kg}$ adalah Rp32.000,00. Pada saat proses produksi, bahan penunjang yang digunakan oleh jamu bubuk adalah garam dan gula dengan takaran yang berbeda, yaitu $5 \mathrm{sdm}$ atau

setara dengan $0,1376 \mathrm{~kg}$ garam dan gula sebanyak $15 \mathrm{~kg}$.

Berdasarkan kriteria penilaian nilai tambah, yaitu jika NT $>0$, berarti pengembangan agroindustri jamu bubuk memberikan nilai tambah (positif). Seluruh jenis produk jamu bubuk memberikan nilai tambah positif, dimana produk temulawak memberikan nilai tambah Rp24.854,42 per $\mathrm{kg}$ bahan baku. Produk kunyit memberikan nilai tambah sebesar Rp25.351,27 per kg bahan baku. Produk jahe memberikan nilai tambah sebesar $\mathrm{Rp} 21.853,94$ per $\mathrm{kg}$ bahan baku, dan produk kencur memberikan nilai tambah sebesar Rp12.352,39 per $\mathrm{kg}$ bahan baku. Hasil perhitungan tersebut disimpulkan bahwa agroindustri jamu bubuk Ibu YY di Desa Asto Mulyo layak untuk dikembangkan kedepannya, dan sejalan dengan penelitian Sari, Zakaria, dan Affandi (2015) tentang kinerja produksi dan nilai tambah agroindustri emping melinjo di Kota Bandar Lampung. Nilai tambah yang diperoleh agroindustri emping melinjo di Kecamatan Rajabasa sebesar $6.838,69$ per $\mathrm{kg}$ bahan baku, dan Kecamatan Sukamaju sebesar $8.238,75$ per $\mathrm{kg}$ bahan baku. 
Tabel 4. Nilai tambah agroindustri jamu bubuk di Desa Asto Mulyo Kecamatan Punggur,2018

\begin{tabular}{|c|c|c|c|c|c|c|}
\hline \multicolumn{7}{|c|}{ Nilai Tambah Jamu Bubuk } \\
\hline No & $\begin{array}{r}\text { Variabel } \\
\end{array}$ & & \multicolumn{4}{|c|}{ Variasi Jamu Bubuk } \\
\hline \multicolumn{3}{|c|}{ Output, input, dan harga } & Temulawak & Kunyit & Kencur & Jahe \\
\hline 1 & Output $(\mathrm{Kg} /$ produksi) & $\mathrm{A}$ & 18,90 & 17,10 & 17,70 & 18,60 \\
\hline 2 & Bahan baku (Kg/produksi) & $\mathrm{B}$ & 15,75 & 14,25 & 14,75 & 15,50 \\
\hline 3 & Tenaga kerja (HOK/produksi) & $\mathrm{C}$ & 3,50 & 3,50 & 3,50 & 3,50 \\
\hline 4 & Faktor konversi & $\mathrm{D}=\mathrm{A} / \mathrm{B}$ & 1,20 & 1,20 & 1,20 & 1,20 \\
\hline 5 & Koefisien tenaga kerja & $\mathrm{E}=\mathrm{C} / \mathrm{B}$ & 0,22 & 0,24 & 0,23 & 0,22 \\
\hline 6 & Harga output $(\mathrm{Rp} / \mathrm{kg})$ & $\mathrm{F}$ & $32.000,00$ & $32.000,00$ & $32.000,00$ & $32.000,00$ \\
\hline 7 & Upah rata-rata tenaga kerja $(\mathrm{Rp} / \mathrm{HOK})$ & $\mathrm{G}$ & $50.000,00$ & $50.000,00$ & $50.000,00$ & $50.000,00$ \\
\hline \multicolumn{7}{|c|}{ Pendapatan dan nilai tambah $(\mathrm{Rp} / \mathrm{kg})$} \\
\hline 8 & Harga bahan baku $(\mathrm{Rp} / \mathrm{kg})$ & $\mathrm{H}$ & $2.500,00$ & $2.000,00$ & $15.000,00$ & $5.500,00$ \\
\hline 9 & Sumbangan input lain (Rp/kg bahan baku) & I & $11.045,58$ & $11.048,73$ & $11.047,61$ & $11.046,06$ \\
\hline 10 & Nilai output & $\mathrm{J}=\mathrm{D} \times \mathrm{F}$ & $38.400,00$ & $38.400,00$ & $38.400,00$ & $38.400,00$ \\
\hline \multirow[t]{2}{*}{11} & a. Nilai tambah & $\mathrm{K}=\mathrm{J}-\mathrm{H}-\mathrm{I}$ & $24.854,42$ & $25.351,27$ & $12.352,39$ & $21.853,94$ \\
\hline & b. Rasio nilai tambah (Persen ) & $\mathrm{L}=\mathrm{K} / \mathrm{J}$ & 64,73 & 66,02 & 32,17 & 56,91 \\
\hline \multirow[t]{2}{*}{12} & a. Imbalan tenaga kerja & $\mathrm{M}=\mathrm{E} X \mathrm{G}$ & $11.111,11$ & $12.280,70$ & $11.864,41$ & $11.290,32$ \\
\hline & b. Bagian tenaga kerja (Persen ) & $\mathrm{N}=\mathrm{M} / \mathrm{K}$ & 44,70 & 48,44 & 96,05 & 51,66 \\
\hline \multirow[t]{2}{*}{13} & a. Keuntungan & $\mathrm{O}=\mathrm{K}-\mathrm{M}$ & $13.743,31$ & $13.070,57$ & 487,99 & $10.563,62$ \\
\hline & b. Tingkat keuntungan (Persen ) & $\mathrm{P}=\mathrm{O} / \mathrm{K}$ & 55,30 & 51,56 & 3,95 & 48,34 \\
\hline \multicolumn{7}{|c|}{ Balas jasa untuk faktor produksi } \\
\hline \multirow[t]{4}{*}{14} & Margin & $\mathrm{Q}=\mathrm{J}-\mathrm{H}$ & $35.900,00$ & $36.400,00$ & $23.400,00$ & $32.900,00$ \\
\hline & a. Keuntungan (Persen ) & $\mathrm{R}=\mathrm{O} / \mathrm{Q}$ & 38,28 & 35,91 & 2,09 & 32,11 \\
\hline & b. Tenaga kerja (Persen ) & $\mathrm{S}=\mathrm{M} / \mathrm{Q}$ & 30,95 & 33,74 & 50,70 & 34,32 \\
\hline & c. Input lain (Persen ) & $\mathrm{T}=\mathrm{I} / \mathrm{Q}$ & 30,77 & 30,35 & 47,21 & 33,57 \\
\hline
\end{tabular}

Sumber : Data primer (diolah), 2018

Keuntungan masing-masing produk berbeda, yaitu keuntungan terbesar ada pada produk temulawak Rp13.743,31, kunyit Rp13.070,57, kemudian jahe sebesar Rp10.563.62, dan terakhir kencur sebesar Rp487,99. Perbedaan keuntungan masing-masing produk dipengaruhi oleh nilai tambah serta imbalan tenaga kerja yang berbeda. Nilai tambah usaha pengolahan jamu bubuk dapat dilihat pada Tabel 4 .

\section{KESIMPULAN}

Kinerja produksi secara keseluruhan sudah baik, dengan nilai produktivitas sebesar $5,16 \mathrm{~kg} / \mathrm{HOK}$, nilai kapasitas produksi telah berproduksi secara baik, dengan kapasitas $\geq 0,50$ atau 50 persen (91\%), total pendapatan seluruh variasi jamu milik Ibu YY pada satu kali produksi adalah Rp1.084.108,00, dan R/C agroindustri jamu bubuk lebih besar dari $1(1,88)$, artinya agroindustri jamu menguntungkan. Nilai tambah pada masingmasing varian jamu berbeda-beda, yaitu Rp25.351,27 per $\mathrm{kg}$ bahan baku kunyit, Rp24.854,42 per $\mathrm{kg}$ bahan baku temulawak, Rp21.853,94 per $\mathrm{kg}$ bahan baku jahe, dan Rp12.352,39 per $\mathrm{kg}$ bahan baku kencur. Perbedaan nilai tambah disebababkan oleh perbedaan harga bahan baku agroindustri jamu bubuk.

\section{DAFTAR PUSTAKA}

Asmara R, Setiawan WN, dan Putri. 2011. Analisis nilai tambah dan efisiensi agroindustri minyak cengkeh. AGRISE, 11(1):45-55. https://agrise.ub.ac.id [20 Desember 2018]

BPS [Badan Pusat Statistik]. 2017. Survei Nilai Produk Domestik Regional Bruto Industri Pengolahan. Badan Pusat Statistik. http://microdata.bps.go.id/mikrodata/cata log/export. [28 Januari 2018].

BPS [Badan Pusat Statistik]. 2018. Sektor Pertanian Kontribusi Wujudkan NawaCita. Badan Pusat Statistik. http://www. Pertanian.go.id/home/?show=news\&act=vie w\&id=3321. [05 April 2019].

BPS [Badan Pusat Statistik] Provinsi Lampung. 2016. Industri Manufaktur Besar dan Sedang. Badan Pusat Statistik Provinsi Lampung. Lampung. http://www.bps.go.id/ pressrelease/2017/02/01/1396/pertumbuhanproduksi-ibs-naik-2-06-persen-dan-imknaik4-88-persen-pada-triwulan-iv-tahun-2016dari-triwulan-iv-tahun-2015. [29 Januari 2018].

BPS [Badan Pusat Statistik] Kecamatan Punggur. 2016 Luas lahan bukan sawah menurut penggunaan di Kecamatan Punggur. Badan 
Pusat Statistik. https://lampungtengahkab. bps.go.id. [29 Januari 2018]

Balitbangtan, Departemen Pertanian. 2007. Prospek dan Arah Pengembangan Agribisnis Tanaman Obat. Edisi Kedua. Jakarta.

Gunawan W. 2014. Bioprospeksi: Upaya Pemanfaatan Tumbuhan Obat Secara Berkelanjutan di Kawasan Konservasi. http://www.fordamof.org/files/3_Bioprospec ting_Upaya_Pemanfaatan_Tumbuhan_ObatWawan_Gunawan. [6 Februari2019].

Kementerian Pertanian. 2015. Statistik Produksi Hortikultura Tahun 2014. Direktorat Jenderal Hortikultura Kementerian Pertanian. Jakarta.

Novia W, Zakaria WA, dan Lestari DAH. 2013. Analisis nilai tambah dan kelayakan pengembangan agroindustri beras siger di Kelurahan Pinang Jaya Kota Bandar Lampung dan Desa Pancasila, Kabupaten Lampung Selatan. JIIA, 1 (3):210-217. http://jurnal.fp.unila.ac.id [24 April 2018]

Nugroho. 2011. Peranan Sektor Pertanian di Indonesia. Departemen Pendidikan
Nasional. Jakarta. http://www.Pertanian.go. $\mathrm{id} /$ home$/$ ?show $=$ news\&act=view\&id=3321. [05 April 2019].

Prasetya H dan Fitri L. 2009. Manajemen Operasi. Media Presindo. Yogyakarta.

Purwanto. 2008. Metode Riset Bisnis. Gramedia Pustaka Utama. Jakarta.

Safitri Y, Abidin Z, dan Rosanti N. 2014. Kinerja dan nilai tambah agroindustri sabut kelapa pada kawasan usaha agroindustri terpadu (kuat) di Kecamatan Pesisir Selatan Kabupaten Pesisir Barat. JIIA, 2(2): 166173. http://jurnal.fp.unila.ac.id [24 Mei 2018]

Sari RM, Zakaria WA, dan Affandi MI. 2015. Kinerja produksi dan nilai tambah agroindustri emping melinjo di Kota Bandar Lampung. JIIA, 3 (1) :48-55. http://jurnal.fp.unila.ac.id [22 Mei 2019]

Soekartawi. 2000. Pengantar Agroindustri. PT. Radja Grafindo Persada. Jakarta.

Undang-Undang Nomor 13 tahun 2010 tentang Hortikultura. Jakarta. 